\title{
Pt doped boron carbide monolayer nanosheet as a work function-type sensor for ibuprofen drug; quantum chemical study
}

liang Wu ( $\sim 9150$ wu@gmail.com )

university of shanghai of science and technology

\section{Research Article}

Keywords: Sensor, Ibuprofen, Adsorption energy, Recovery time

Posted Date: February 24th, 2021

DOI: https://doi.org/10.21203/rs.3.rs-220265/v1

License: (c) (i) This work is licensed under a Creative Commons Attribution 4.0 International License.

Read Full License 
Pt doped boron carbide monolayer nanosheet as a work function-type sensor for ibuprofen drug; quantum chemical study

\author{
Liang $\mathrm{Wu}^{1 *}$ \\ ${ }^{1}$ College of Science, University of Shanghai for Science and Technology, Shanghai, China
}

Email address: 9150wu@gmail.com 


\begin{abstract}
Through density functional theory (DFT), the sensitivity of the Pt-doped and the pristine $\mathrm{BC}_{3}$ nanosheets to ibuprofen (IBP) was scrutinized. The IBP drug does not impact the electronic properties evaluated for the pristine $\mathrm{BC}_{3}$. However, its sensitivity and reactivity are increased to the IBP drug to a great extent after doping it by $\mathrm{Pt}$. Unlike the pristine $\mathrm{BC}_{3}$, the adsorption of the IBP drug decreases the HOMO-LUMO gap associated with the Pt-doped $\mathrm{BC}_{3}$ sheet from 1.29 to $1.04 \mathrm{eV}$, which improves the electrical conductivity. In addition, the adsorption of the IBP drug will mainly impact the work function of the Pt-doped $\mathrm{BC}_{3}$ sheet, which in turn modifies the electron emission current from its sheet. This verifies that the Pt-doped $\mathrm{BC}_{3}$ sheet can be utilized as a work-function-type sensor to detect the IBP drug. For desorption of the IBP drug, the recovery time of the $\mathrm{Pt}_{-} \mathrm{BC}_{3}$ nanosheet is short, i.e., $5.65 \mathrm{~ms}$, which is another advantage of this sheet.
\end{abstract}

Keywords: Sensor, Ibuprofen, Adsorption energy, Recovery time 


\section{Introduction}

Ibuprofen (IBP) is one of the commonly used nonsteroidal drugs that is prescribed as a painkiller and an antipyretic agent, which is used to treat inflammation [1]. By blocking the enzyme cyclooxygenase, IBP can inhibit prostaglandin biosynthesis and most of it is usually metabolized in liver to hydroxyl as well as carboxyl metabolites IBP metabolites, while only less than $10 \%$ is excreted in urine and bile without change [2,3]. Based on the World Health Organization, the recommended dosage for IBF is $1200 \mathrm{mg}$, and it overdosage can lead to severe side effects [4]. IBP is a common analyte in pharmaceutical analysis according to its widespread availability. Based on medicinal purposes and the pharmaceutical importance of IBP, we need a highly efficient method to detect and control this drug in various biological fluids[59].

Owing to some of the outstanding properties of nanomaterials, including flexible lifetime, considerable stability, unsubstantial size, good biocompatibility, large specific surface area, and appropriate surface modification characteristics, they are now the most ideal candidates to detect biological and chemical species [8-10]. Also, numerous clinical applications of such materials have already been reported owing to their controllable characteristics [13]. Compared to conventional drug detection methods, the side effects of nanomaterials have been drastically reduced since their superior properties have improved the efficiency and bioactivity of these materials [14]. In addition, they provide long-term blood circulation, as well as maintaining the biological activity of a drug [14]. Among nanomaterials, graphene and associated derivatives in their pristine form, and two-component graphene-like materials have been used successfully in medical applications as two-dimensional (2D) materials [15]. These materials are mainly provided from two major B/C components in different ratios [16-18] such as the boron carbide 
nanotube shaped $\mathrm{BC}_{\mathrm{n}}$ structure having boron to carbon with atomic ratio of 1:3 that has chemical stability [17]. Similar to graphene, the formation of $\mathrm{BC}_{3}$ nanosheets is carried out via rolling $\mathrm{a}_{\mathrm{BC}_{3}}$ nanosheet along the chiral vector. It is worth noting that because of the insignificant stability of boron-boron bonds, there only exist carbon-boron and boron-carbon bonds in this structure $[19,20]$. Numerous pieces of research have been carried out into the electronic and structural properties of $\mathrm{BC}_{3}$ nanosheets [21]. In the current study, we investigated the interaction behavior and the electronic response of the $\mathrm{Pt}$-doped and pristine $\mathrm{BC}_{3}$ nanosheets to the IBP drug via employing DFT.

\section{Computational methods}

By utilizing GAMESS software, full geometry as well as the optimized energy of the Pt-doped $\mathrm{BC}_{3}$ nanosheet and the pristine $\mathrm{BC}_{3}$ nanosheet were computed via implementing the $\mathrm{B} 3 \mathrm{LYP}$ functional with the 6-31G (d) basis set [22]. B3LYP-D, as an experimental dispersion term, was introduced to the basis set to raise the exactness of the data computed, particularly related to components with noncovalent bonds. The B3LYP is a common functional employed in studies on synthesized nanostructures $[23,24]$, through which accurate results are obtained for III-V semiconductors [25]. GaussSum software was utilized for carrying out the DOS calculations [26]. The energy of adsorption( $\left.\mathrm{E}_{\mathrm{ad}}\right)$ is estimated based on the equation below:

$$
\mathrm{E}_{\mathrm{ad}}=\mathrm{E}\left(\mathrm{IBP} / \mathrm{BC}_{3}\right)-\mathrm{E}\left(\mathrm{BC}_{3}\right)-\mathrm{E}(\mathrm{IBP})+\mathrm{E}(\mathrm{BSSE})
$$

Where $\mathrm{E}\left(\mathrm{ACE} / \mathrm{BC}_{3}\right)$ is the total adsorption energy of the $\mathrm{ACE}$ drug on the $\mathrm{BC}_{3}$ sheet surface; $\mathrm{E}\left(\mathrm{BC}_{3}\right)$ the total energy of the $\mathrm{BC}_{3}$ sheet; and $\mathrm{E}$ (BSSE) the basis set superposition.

$$
\Delta \mathrm{E}_{\mathrm{g}}=\left[\left(\mathrm{E}_{\mathrm{g} 2}-\mathrm{E}_{\mathrm{g} 1}\right) / \mathrm{E}_{\mathrm{g} 1}\right] \times 100 \%
$$

Where $\mathrm{E}_{\mathrm{g} 1}$ represents the adsorption energy of the bare $\mathrm{BC}_{3}$ nanosheet and $\mathrm{E}_{\mathrm{g} 2}$ represents the 
energy related to the adsorption of the ACE drug molecule adsorbed onto the sheet.

\section{Results and discussion}

\subsection{IBP molecule and its relevant adsorption geometries on the surface of $B C_{3}$}

As can be seen in Fig. 1, the $\mathrm{BC}_{3}$ sheet possess a lattice structure that is the same as graphene, in which $6 \mathrm{C}$ atoms and 2 boron atoms form each unit cell, unlike conventional $\mathrm{BN}$ with $2 \mathrm{D}$ structures. The estimated $\mathrm{B}-\mathrm{C}$ bond length was 1.56 , and the estimated $\mathrm{C}-\mathrm{C}$ bond length

was $1.42 \AA$. According to Fig. 1, there exist two types of hollow sites in $\mathrm{BC}_{3}$, one of which is the hexagon center $\mathrm{C}_{6}$ which is hollow and the other is the hexagon $\mathrm{C}_{4} \mathrm{~B}_{2}$. The $\mathrm{E}_{\mathrm{g}}$ value (Table 1) as well as the computed DOS plot indicates that the pristine sheet is considered to be a semiconductor. In addition, the optimized geometry and the HOMO and LUMO of the IBP drug are depicted in Fig.2. In the IBP molecule, the HOMO level, with energy of $-5.92 \mathrm{eV}$, located above the corresponding level in all $\mathrm{C}-\mathrm{C}$ atoms, and on the electronegative oxygen atom in the molecule. However, the LUMO level $(0.26 \mathrm{eV})$ located on the ring carbon atoms, nearly above the carboxyl oxygen atom of IBP.

The axis of the MF drug might be parallel to the $\mathrm{BC}_{3}$ sheet surface and the tendency of the species was assessed to the adsorbent by the energies of the adsorption interaction associated with the drug that was attached to the BC3 sheets. The different frameworks that represent the interactions between the MF drug and the $\mathrm{BC}_{3}$ sheet are shown in Fig. 3 (a,b). The oxygen atom of hydroxyl groups $(-\mathrm{OH})$ of the IBP drug was near the surface of the $\mathrm{BC}_{3}$ sheets in configuration I. In this configuration, the weak interactions were identified between the hydroxyl group of the IBP drug and the B atoms (side-on) and the corresponding adsorption energy was $6.27 \mathrm{kcal} / \mathrm{mol}$. In addition, the $\mathrm{B}-\mathrm{O}$ bond distance in configuration $\mathbf{I}$ was computed to be approximately $1.91 \AA$ A. In configuration II, the IBP drug adsorption is parallel to the $\mathrm{BC}_{3}$ 
nanosheets and Fig. 3b shows the related configuration in the position described. . In configurations II, the IBP drug connected with its oxygen atom of carboxyl groups $(-\mathrm{C}=\mathrm{O})$ to the $\mathrm{BC}_{3}$ nanosheet. The distance between the $\mathrm{IBP}$ drug and $\mathrm{B}$ in the $\mathrm{BC}_{3}$ nanosheet $(\mathrm{O}-\mathrm{B}$ bond length) was approximately $1.84 \AA$, and the energy of adsorption was calculated to be -8.24 $\mathrm{kcal} / \mathrm{mol}$. Similar to configurations $\mathbf{I}$, the interaction between the IBP drug and the $\mathrm{BC}_{3}$ nanosheet was not strong. Moreover, in the contact area, the structure of the $\mathrm{BC}_{3}$ nanosheet did not change significantly. The mean $\mathrm{C}-\mathrm{B}-\mathrm{C}$ distance was about $0.23 \AA$ and the associated bond angle was approximately $114.2^{\circ}$ in this type of adsorption. In the pristine $\mathrm{BC}_{3}$ sheets, the C-B bond length was nearly $1.55 \AA$, whereas this bond length was slightly extended in both drug complexes with $\mathrm{BC}_{3}$. Compared to configuration $\mathbf{I}$, the charge transfer of the IBP drug which was adsorbed onto the $\mathrm{BC}_{3}$ complex is less, i.e., approximately $0.3 \mathrm{e}$, in configuration II, and it has more stability regarding the energy of adsorption. The electronic characteristics and the adsorption energy of the various $\mathrm{IBP}-\mathrm{BC}_{3}$ configurations have been recapitulated in Table 1. Based on Table 1, complexes that possess more stable configurations have the ability to reduce the HOMO level from $-4.25 \mathrm{eV}$ to $-4.32 \mathrm{eV}$ in the pristine sheets. Also, compared to its pristine form, this complex has decreased the Eg value by $9.56 \%$. The change in the $\mathrm{E}_{\mathrm{g}}$ value can be considered as a suitable factor that determines the sensitivity of an adsorbent to an adsorbate since the $\mathrm{E}_{\mathrm{g}}$ value corresponds to the population of conduction elections as stated by Eq. 3 [27].

$$
\mathrm{N}=\mathrm{A} \mathrm{T}^{3 / 2} \exp \left(-\mathrm{Eg}_{\mathrm{g}} / 2 \mathrm{kT}\right)
$$

Where A (electrons $/ \mathrm{m}^{3} \mathrm{~K}^{3 / 2}$ ) represents a constant, and $\mathrm{k}$ represents the Boltzmann's constant. The results obtained are in good agreement with the experimental results obtained in the literature [52-54]. Based on Eq. 3, the population of conduction electrons increases exponentially as $E_{\mathrm{g}}$ decreases, which is changed into an electrical signal and its magnitude is determined by the 
IBP drug concentration in the urine and bile mediums. The $\mathrm{BC}_{3}$ nanosheet produces electrical noise which can determine whether the IBP drugs exist. Moreover, the work function $(\Phi)$ and the Fermi level are the two important variables of $\mathrm{BC}_{3}$ nanosheets which have to be inspected. The Kelvin method is an important part of the process of $\Phi$-type gas sensors. For the measurement of the work function of a sample prior to and following the adsorption of the IBP molecule by the $\mathrm{BC}_{3}$ sheet, a Kelvin probe is employed in this method. There will be a change in the gate voltage and the electrical noise will be produced for recognizing the drug in case the adsorbent work function is impacted by the IBP adsorption to a great extent [28]. Work function $(\Phi)$ is the least amount of work needed for removing an electron from the Fermi level to infinity, computed as follows:

$$
\Phi=\mathrm{V}_{\mathrm{el}(+\infty)}-\mathrm{EF}_{\mathrm{F}}
$$

Where $V_{\text {el }}(+\infty)$ shows the electrostatic potential associated with an electron which is located far from the substance surface, assumed to be 0 , and the Fermi level is shown by EF. According to Eq. 4, in case the electrostatic potential energy is assumed to be 0 , then $\Phi=-E F$, and the Fermi level energy will be computed as follows:

$\mathrm{E}_{\mathrm{F}}=\mathrm{E}_{\mathrm{HOMO}}+\left(\mathrm{E}_{\mathrm{LUMO}}-\mathrm{EHOMO}\right) / 2$

Based on the Richardson-Dushman equation, when the Fermi level changes, there will be a shift in the field emissions as well since the current densities of an electron and the work function value are correlated [29]:

$$
\mathrm{j}=\mathrm{AT}^{2} \exp (-\Phi / \mathrm{kT})
$$

In which A shows the Richardson constant $\left(\mathrm{A} / \mathrm{m}^{2}\right)$, and $\mathrm{T}$ shows the absolute temperature $(\mathrm{K})$. Based on Table 1, the adsorption of IBP on the BC3 surface reduces $\Phi$ by $2.75 \%$ relative to the pristine $\mathrm{BC}_{3}$ nanosheet in configuration II. There is not a significant change in the the current 
density of electrons that emitted from the $\mathrm{BC}_{3}$ nanosheet surface. Therefore, we can conclude that the $\mathrm{BC}_{3}$ nanosheet is not a work function-type sensor and cannot detect or adsorb the IBP drug.

\subsection{Pt-doped $B C_{3}$ nanosheet}

The Pt atom was replaced by the B atom for scrutinizing the impacts upon the electronic and structural characteristics of the $\mathrm{BC}_{3}$ surface. Fig. $\mathbf{4} \mathbf{b}$ depicts the optimized structure of heteroatoms that was doped with $\mathrm{Pt}$ in the $\mathrm{BC}_{3}$ nanosheet. Doping the $\mathrm{Pt}$ atom, because of its larger size than $\mathrm{B}$, will reduce the repulsion and stress in the $\mathrm{BC} 3$ structure. Compared to the length of the $\mathrm{B}-\mathrm{C}$ bond in the pristine $\mathrm{BC}_{3}$, the $\mathrm{Pt}-\mathrm{C}$ bond length was significantly longer, which was calculated to be $1.92 \AA$. Also, compared to the $\mathrm{C}-\mathrm{B}-\mathrm{C}$ bond angle in the pristine $\mathrm{BC}_{3}$ $\left(117^{\circ}\right)$, the C-Pt-C bond angle in the Pt-doped sheet is larger, which was calculated to be $121^{\circ}$. In the Pt-doped $\mathrm{BC}_{3}$ nanosheet, the $\mathrm{Eg}_{\mathrm{g}}$ value was computed to be approximately $1.29 \mathrm{eV}$, being smaller compared to the pure $\mathrm{BC}_{3}$ nanosheet. At the doped sites, the $\mathrm{Si}$ atom will act as affinity center for the ACE drug to be chemisorbed.

Afterward, by putting the species above the Pt atom with the IBP oxygen atom of carboxyl groups $(-\mathrm{C}=\mathrm{O})$, above the $\mathrm{Pt}$ in the doped $\mathrm{BC}_{3}$, the interaction between the Pt-doped $\mathrm{BC}_{3}$ and the IBP drug was inspected, as depicted in Fig. During the interaction, the Pt-O bond distance was calculated to be approximately $1.62 \AA$ after the interaction of the Pt-doped $\mathrm{BC}_{3}$ with the IBP drug. In comparison with the pristine $\mathrm{BC}_{3}$ nanosheet, the Pt-doped $\mathrm{BC}_{3}$ sheet exhibited enhanced performance because of its higher charge transfer value of $0.45 \mathrm{e}$, more negative energy of adsorption, and stronger adsorption between the Pt-doped $\mathrm{BC}_{3}$ and the IBP drug. According to the interaction mechanism, it can be suggested that the oxygen atom, a region rich in electrons, binds to the exposed $\mathrm{Pt}$, a region poor in electrons. 
According to the results, Pt doping is very effective in creating a more favorable sensor for the IBP drug, unlike the pristine sample. In addition, the adsorption energy of the IBP drug in the Pt-doped $\mathrm{BC}_{3}$ nanosheet was computed to be $-23.56 \mathrm{kcal} / \mathrm{mol}$. The electronic properties will be altered dramatically by the IBP drug reaction with Pt-doped $\mathrm{BC}_{3}$ and after the the complex is formed based on DOS plot in Fig.4 $\mathbf{c}$ and data in Table 2. Unsurprisingly, in the complex, the LUMO energy associated with the nitrogen atom was stabilized by the adsorption process. Since Pt interacts with the oxygen atom of carboxyl groups of electron lone pairs, this change is perfectly acceptable, resulting in significant changes in the LUMO level in the Pt-doped $\mathrm{BC}_{3}$. Also, the considerable stabilization of the LUMO energy is considered to be the cause of the substantial decrease in the adsorption energy of the Pt-doped $\mathrm{BC}_{3}$, which was reduced from 1.29 to 1.04 .

According to Eq. 3, this decrease will enhance the electrical conductivity of the Pt-BC3. The change in the electrical conductivity corresponds to the electrical signal, indicating the presence of the IBP drug in the urine and bile mediums. Hence, $\mathrm{Pt}_{-} \mathrm{BC}_{3}$ can be considered as a cheap and good electronic sensor to detect the IBP drug. The $\mathrm{Pt}_{-} \mathrm{BC}_{3}$ work function value changed dramatically from $4.88 \mathrm{eV}$ in $\mathrm{Zn}-\mathrm{BC}_{3}$ to $3.89 \mathrm{eV}$ in the IBP complex. Therefore, with the adsorption of the IBP drug, the electron current density that emitted from the $\mathrm{Pt}-\mathrm{BC}_{3}$ nanosheet is reduced, enabling the detection of the IBP adsorbents. As a $\Phi$-type sensor, the IBP drug can be detected using Pt-BC 3 .

In sensor applications, one of the preconditions for an acceptable sensor is a facilitated desorption, and because of this reason, chemical interactions that are too strong are not favored. In a strict sense, too strong adsorptions lead to longer recovery times, not advantageous for sensor applications. Based on the transition-state theory, longer recovery time is expected in 
strong adsorptions as follows [30]:

$$
\tau=v_{0}^{-1} \exp \left(-\mathrm{Ead}_{\mathrm{a}} / \mathrm{kT}\right)
$$

Where the attempt frequency is represented by $v_{0}$. In case of employing the vacuum ultra-violet

light $\left(\mathrm{v} \sim 10^{12} \mathrm{~s}^{-1}\right)$, it will take approximately $5.65 \mathrm{~ms}$ for the IBP drug to recover from the surface of the Pt-doped $\mathrm{BC}_{3}$ sheet at room temperature. It should be noted that at different temperatures, this time can be decreased to some extent. The associated recovery time for the Pt-doped is short, being adequate for sensor usability in IBP.

\section{Conclusions}

In this paper, the impact of $\mathrm{Pt}$ doping was scrutinized upon the sensitivity of the $\mathrm{BC}_{3}$ nanosheet to the IBP drug by employing DFT calculations using 6-31G (d) basis set. The findings showed that the IBP drug was adsorbed onto the $\mathrm{Pt}-\mathrm{BC}_{3}$ nanosheet to a great extent with the adsorption energy of roughly $-23.56 \mathrm{kcal} / \mathrm{mol}$. When the pristine $\mathrm{BC}_{3}$ sheet is doped with $\mathrm{Pt}$, the absorption process of the IBP drug is enhanced to this substrate, which is possible to be utilized as a $\Phi$-type sensor to detect the IBP drug. Also, the recovery time for the IBP drug to the $\mathrm{Pt}-\mathrm{BC}_{3}$ nanosheet was computed to be approximately $5.65 \mathrm{~ms}$ by employing ultra-violet vacuum light at ambient temperature.

\section{Disclosure statement}

-Conflicts of Interest: None

-Ethical Approval: Not required

-Consent to Participate: confirmed

-Consent to Publish: confirmed

-Authors Contribution: all authors have same contribution

-Funding: None

-Availability of data and materials: confirmed 


\section{Reference}

1. Marsik P, Rezek J, Židková M, Kramulová B, Tauchen J, Vaněk T (2017) Non-steroidal antiinflammatory drugs in the watercourses of Elbe basin in Czech Republic. Chemosphere 171:97105

2. Aranda JV, Salomone F, Valencia GB, Beharry KD (2017) Non-steroidal anti-inflammatory drugs in newborns and infants. Pediatric Clinics 64 (6):1327-1340

3. Simmons DL, Wagner D, Westover K (2000) Nonsteroidal anti-inflammatory drugs, acetaminophen, cyclooxygenase 2, and fever. Clinical infectious diseases 31 (Supplement_5):S211-S218

4. Sözen H, Gönen I, Sözen A, Kutlucan A, Kalemci S, Sahan M (2013) Application of ATC/DDD methodology to eveluate of antibiotic use in a general hospital in Turkey. Annals of clinical microbiology and antimicrobials 12 (1):23

5. Rezaeifar Z, Es' haghi Z, Rounaghi GH, Chamsaz M (2016) Hyperbranched polyglycerol/graphene oxide nanocomposite reinforced hollow fiber solid/liquid phase microextraction for measurement of ibuprofen and naproxen in hair and waste water samples. Journal of Chromatography B 1029:81-87

6. Madikizela LM, Chimuka L (2016) Determination of ibuprofen, naproxen and diclofenac in aqueous samples using a multi-template molecularly imprinted polymer as selective adsorbent for solid-phase extraction. Journal of pharmaceutical and biomedical analysis 128:210-215

7. Racamonde I, Rodil R, Quintana JB, Sieira BJ, Kabir A, Furton KG, Cela R (2015) Fabric phase sorptive extraction: A new sorptive microextraction technique for the determination of 
non-steroidal anti-inflammatory drugs from environmental water samples. Analytica chimica acta $865: 22-30$

8. Kubáň P, Boček P (2016) Simultaneous micro-electromembrane extractions of anions and cations using multiple free liquid membranes and acceptor solutions. Analytica chimica acta 908:113-120

9. Švorc L', Strežová I, Kianičková K, Stanković DM, Otř́sal P, Samphao A (2018) An advanced approach for electrochemical sensing of ibuprofen in pharmaceuticals and human urine samples using a bare boron-doped diamond electrode. Journal of Electroanalytical Chemistry 822:144152. doi:https://doi.org/10.1016/j.jelechem.2018.05.026

10. Hibino H, Kageshima H, Kotsugi M, Maeda F, Guo F-Z, Watanabe Y (2009) Dependence of electronic properties of epitaxial few-layer graphene on the number of layers investigated by photoelectron emission microscopy. Physical Review B 79 (12):125437

11. Lee C, Yan H, Brus LE, Heinz TF, Hone J, Ryu S (2010) Anomalous lattice vibrations of single-and few-layer MoS2. ACS nano 4 (5):2695-2700

12. Hoshino A, Fujioka K, Oku T, Suga M, Sasaki YF, Ohta T, Yasuhara M, Suzuki K, Yamamoto K (2004) Physicochemical properties and cellular toxicity of nanocrystal quantum dots depend on their surface modification. Nano Letters 4 (11):2163-2169

13. Hubbell JA, Chilkoti A (2012) Nanomaterials for drug delivery. Science 337 (6092):303-305 14. Ma P, Mumper RJ (2013) Paclitaxel nano-delivery systems: a comprehensive review. Journal of nanomedicine \& nanotechnology 4 (2):1000164

15. Alinejad A, Raissi H, Hashemzadeh H (2019) Understanding co-loading of doxorubicin and camptothecin on graphene and folic acid-conjugated graphene for targeting drug delivery: 
classical MD simulation and DFT calculation. Journal of Biomolecular Structure and Dynamics:1-9

16. Golberg D, Bando Y, Bourgeois L, Kurashima K, Sato T (2000) Large-scale synthesis and HRTEM analysis of single-walled $\mathrm{B}$-and $\mathrm{N}$-doped carbon nanotube bundles. Carbon 38 (14):2017-2027

17. Hernandez E, Goze C, Bernier P, Rubio A (1998) Elastic properties of C and B x C y N z composite nanotubes. Physical Review Letters 80 (20):4502

18. Golberg D, Bando Y, Han W, Kurashima K, Sato T (1999) Single-walled B-doped carbon, $\mathrm{B} / \mathrm{N}$-doped carbon and $\mathrm{BN}$ nanotubes synthesized from single-walled carbon nanotubes through a substitution reaction. Chemical Physics Letters 308 (3-4):337-342

19. Wang Q, Chen L-Q, Annett JF (1996) Stability and charge transfer of C 3 B ordered structures. Physical Review B 54 (4):R2271

20. Tanaka H, Kawamata Y, Simizu H, Fujita T, Yanagisawa H, Otani S, Oshima C (2005) Novel macroscopic BC3 honeycomb sheet. Solid state communications 136 (1):22-25

21. Yi J-Y, Bernholc J (1993) Atomic structure and doping of microtubules. Physical Review B $47(3): 1708$

22. Schmidt MW, Baldridge KK, Boatz JA, Elbert ST, Gordon MS, Jensen JH, Koseki S, Matsunaga N, Nguyen KA, Su S (1993) General atomic and molecular electronic structure system. Journal of computational chemistry 14 (11):1347-1363

23. Beheshtian J, Peyghan AA, Bagheri Z (2012) Detection of phosgene by Sc-doped BN nanotubes: a DFT study. Sensors and Actuators B: Chemical 171:846-852 
24. Abdulsattar MA (2011) SiGe superlattice nanocrystal pure and doped with substitutional phosphorus single atom: Density functional theory study. Superlattices and Microstructures 50 (4):377-385

25. Tomić S, Montanari B, Harrison N (2008) The group III-V's semiconductor energy gaps predicted using the B3LYP hybrid functional. Physica E: Low-dimensional Systems and Nanostructures 40 (6):2125-2127

26. O’Boyle MMT (2008) A L. and Langer, K MJ Comput. Chem 29:839

27. Ahmadi Peyghan A, Hadipour NL, Bagheri Z (2013) Effects of Al doping and doubleantisite defect on the adsorption of $\mathrm{HCN}$ on a $\mathrm{BC} 2 \mathrm{~N}$ nanotube: density functional theory studies. The Journal of Physical Chemistry C 117 (5):2427-2432

28. Korotcenkov G (2013) Handbook of gas sensor materials. In: Conventional Approaches, vol 1. Springer,

29. Richardson O (1924) Electron emission from metals as a function of temperature. Physical Review 23 (2):153

30. Hadipour NL, Ahmadi Peyghan A, Soleymanabadi H (2015) Theoretical study on the Aldoped $\mathrm{ZnO}$ nanoclusters for $\mathrm{CO}$ chemical sensors. The Journal of Physical Chemistry C 119 (11):6398-6404 


\section{Figure captions}

Fig. 1. Optimized structure of $\mathrm{BC}_{3}$ nanosheet and DOS plots.

Fig. 2. (a) Optimized structure, (b) HOMO and (c) LUMO profile of IBP drug.

Fig. 3. Different optimized configurations (a) I and (b) II of IBP-BC 3 complex.

Fig. 4. Optimized structure of (a) $\mathrm{Pt} @ \mathrm{BC}_{3}+\mathrm{IBP}$, (b) Pt doped $\mathrm{BC}_{3}$ and (c) comparative DOS plots. 
Table1. The $\mathrm{E}_{\mathrm{ad}}$ indicates the adsorption energy of IBP molecules on the $\mathrm{BC}_{3}$ in $\mathrm{kcal} / \mathrm{mol}$. HOMO energies (Еномо), LUMO energies (Elumo), HOMO-LUMO energy gap (Eg), Fermi level energy $\left(\mathrm{EF}_{\mathrm{F}}\right)$, and work function $(\Phi)$ of $\mathrm{BC}_{3}$ nanosheet and its complexes with different configurations are in $\mathrm{eV} . \% \Delta \mathrm{Eg}_{\mathrm{g}}$ and $\% \Delta \Phi$ indicate the change of $\mathrm{Eg}$ and $\Phi$ after adsorption process, respectively.

\begin{tabular}{ccccccccc}
\hline Structure & $\mathrm{E}_{\mathrm{ad}}$ & $\mathrm{E}_{\mathrm{HOMO}}$ & $\mathrm{E}_{\mathrm{F}}$ & $\mathrm{E}_{\mathrm{LUMO}}$ & $\mathrm{Eg}_{\mathrm{g}}$ & $\% \Delta \mathrm{Eg}_{\mathrm{g}}$ & $\Phi$ & $\% \Delta \Phi$ \\
\hline $\mathbf{B C}_{\mathbf{3}}$ & - & -5.77 & -5.04 & -4.32 & 1.45 & - & 5.04 & - \\
\hline IBP & - & -5.92 & -2.83 & 0.26 & 6.18 & - & 2.83 & - \\
\hline Configuration I & -6.27 & -5.65 & -4.96 & -4.28 & 1.37 & -5.55 & 4.96 & -1.58 \\
\hline Configuration II & -8.24 & -5.56 & -4.90 & -4.25 & 1.31 & -9.65 & 4.90 & -2.77 \\
\hline
\end{tabular}


Table2. The $\mathrm{E}_{\mathrm{ad}}$ indicates the adsorption energy of IBP molecules on the $\mathrm{Pt}$ doped $\mathrm{BC}_{3}$ in kcal/mol. HOMO energies (Еномо), LUMO energies (Elumo), HOMO-LUMO energy gap (Eg), Fermi level energy $\left(\mathrm{EF}_{\mathrm{F}}\right)$, and work function $(\Phi)$ of $\mathrm{Pt}$ doped $\mathrm{BC}_{3}$ nanosheet and its complexes in eV. $\% \Delta \mathrm{E}_{\mathrm{g}}$ and $\% \Delta \Phi$ indicate the change of $\mathrm{Eg}_{\mathrm{g}}$ and $\Phi$ after adsorption process, respectively.

\begin{tabular}{ccccccccc}
\hline Structure & $\mathrm{E}_{\mathrm{ad}}$ & $\mathrm{E}_{\mathrm{HOMO}}$ & $\mathrm{E}_{\mathrm{F}}$ & $\mathrm{E}_{\mathrm{LUMO}}$ & $\mathrm{E}_{\mathrm{g}}$ & $\% \Delta \mathrm{Eg}_{\mathrm{g}}$ & $\Phi$ & $\% \Delta \Phi$ \\
\hline Pt doped BC 3 & - & -5.53 & -4.88 & -4.24 & 1.29 & - & 4.88 & - \\
\hline $\mathbf{P t} @ \mathbf{B C}_{\mathbf{3}}+\mathbf{I B P}$ & -23.56 & -4.41 & -3.89 & -3.37 & 1.04 & -19.37 & 3.89 & -20.28 \\
\hline
\end{tabular}


Fig. 1.
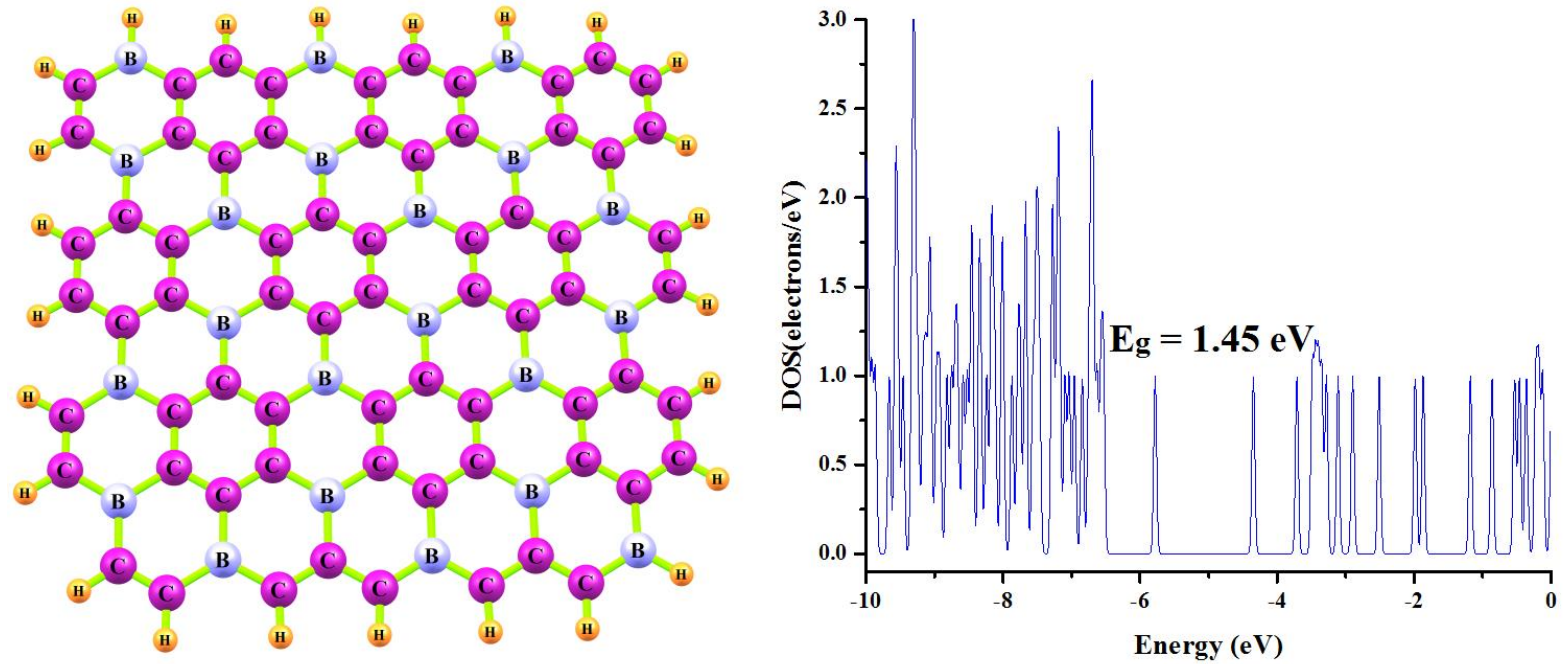
Fig. 2.

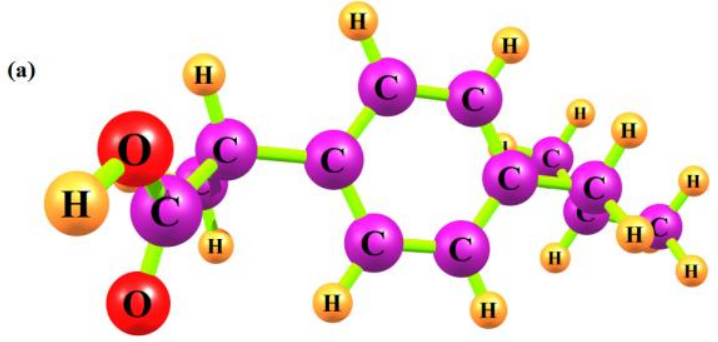

(b)

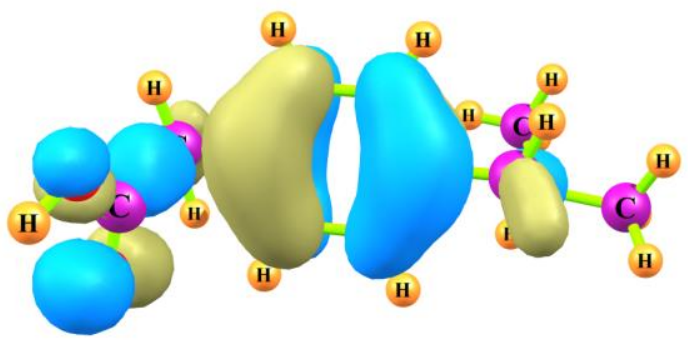

(c)

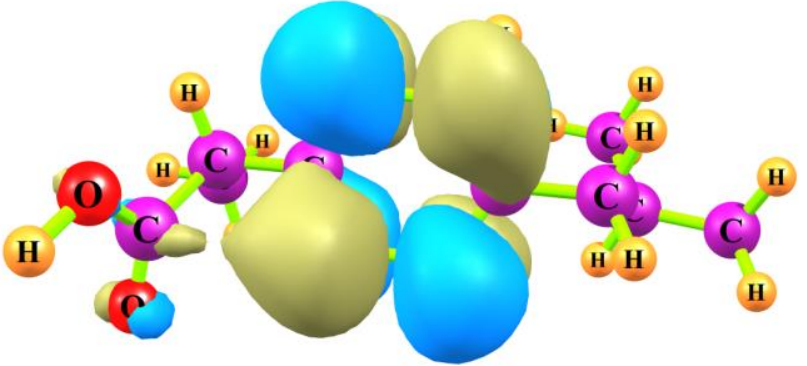


Fig. 3.
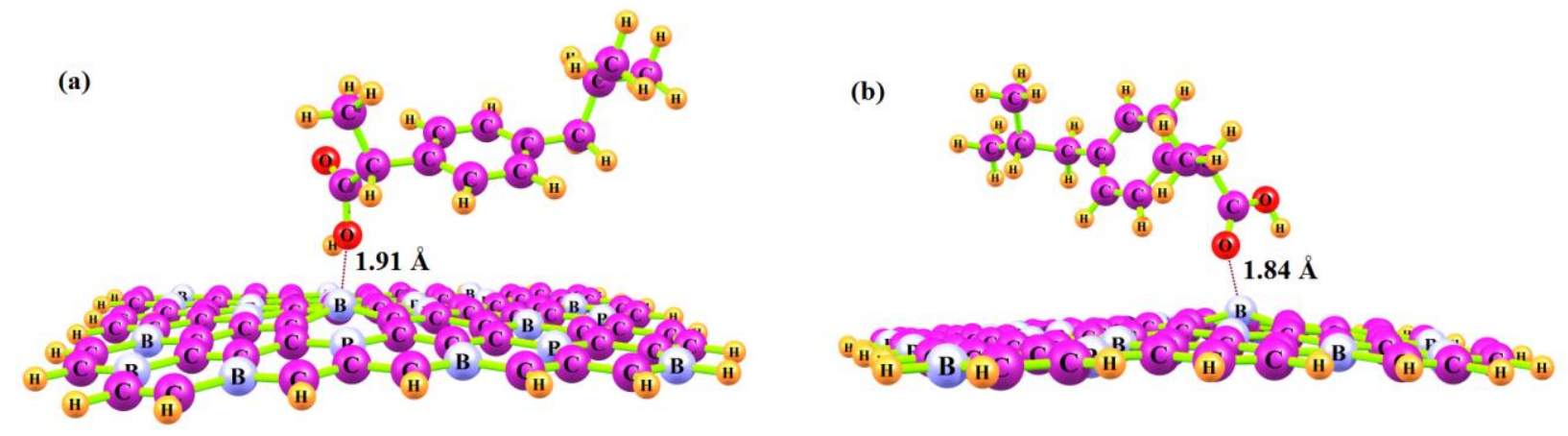
Fig. 4.
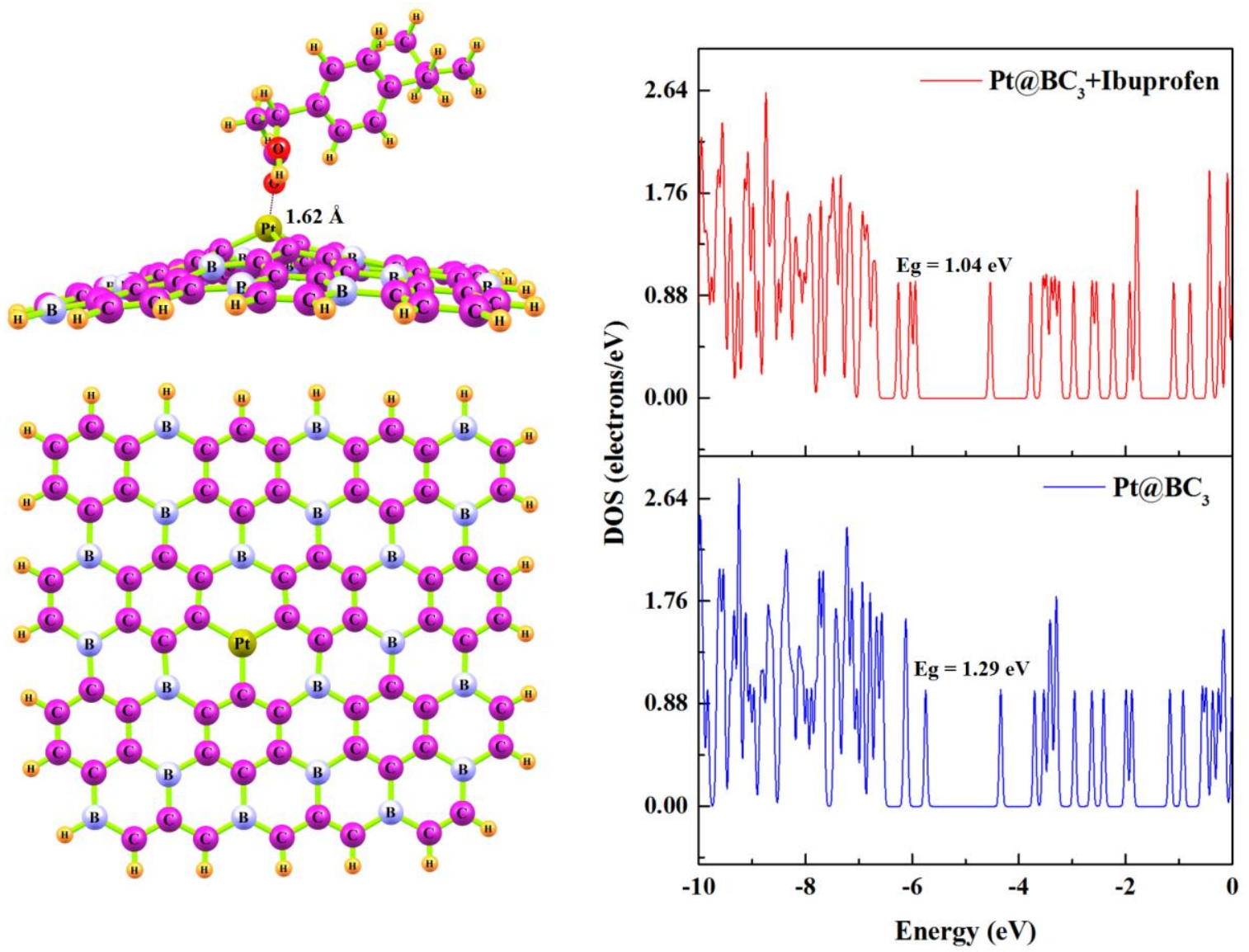
Figures
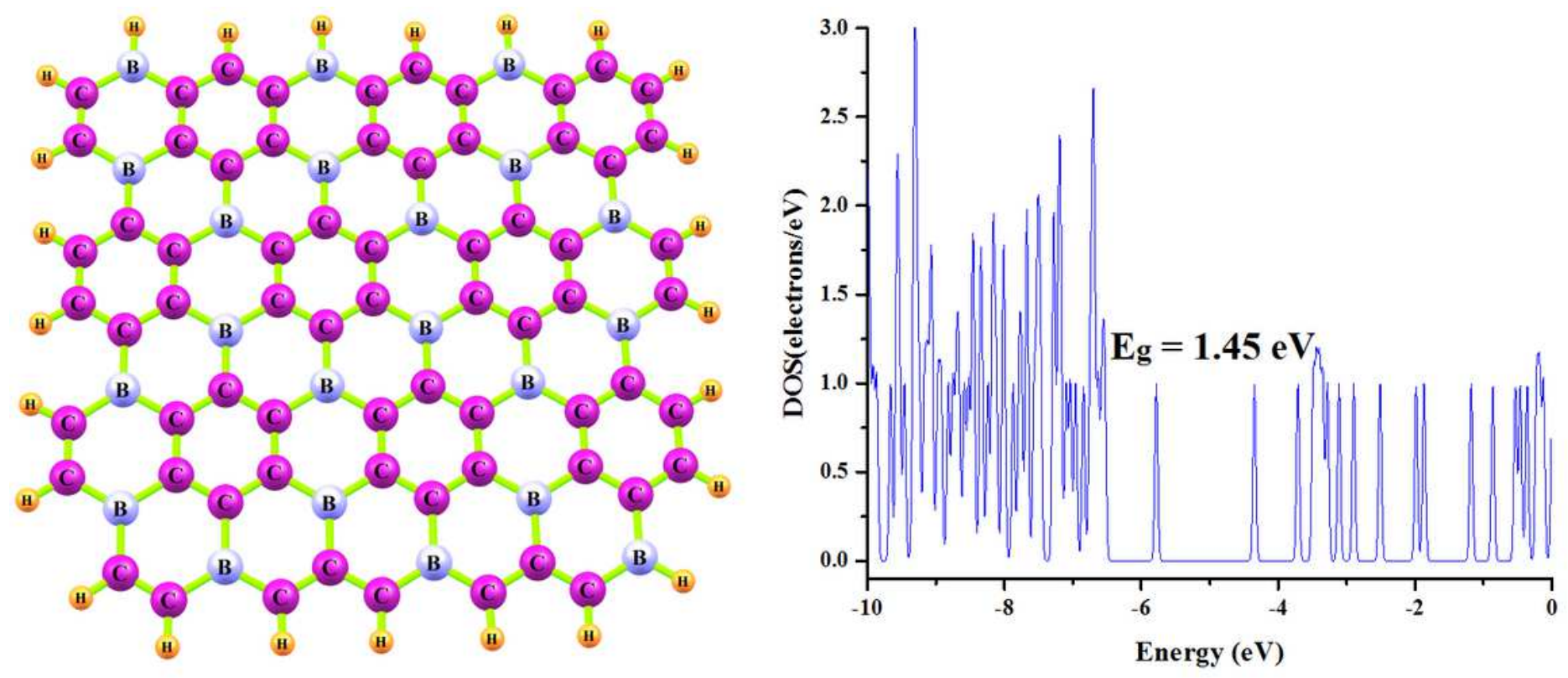

Figure 1

Optimized structure of BC3 nanosheet and DOS plots.

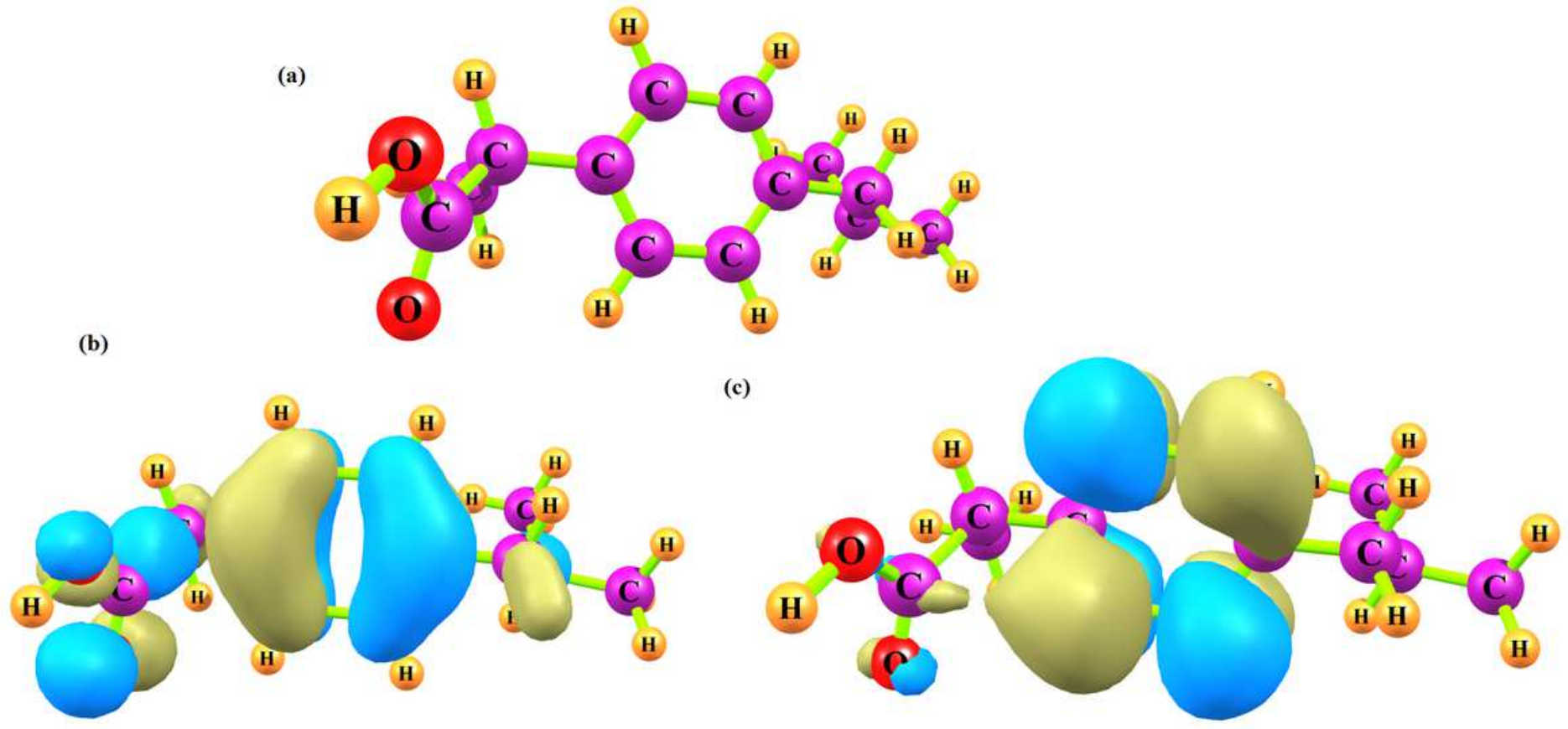

Figure 2

(a) Optimized structure, (b) HOMO and (c) LUMO profile of IBP drug. 
(a)

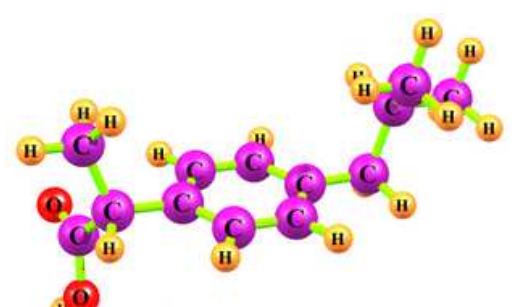

$1.91 \AA$

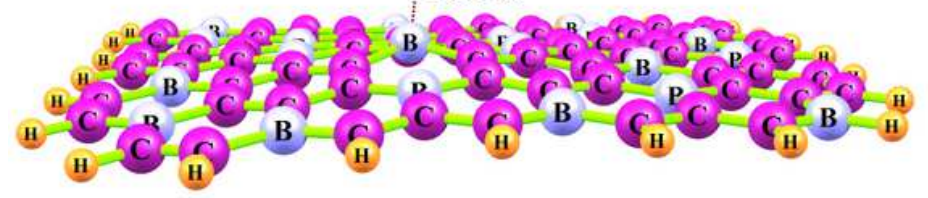

(b)
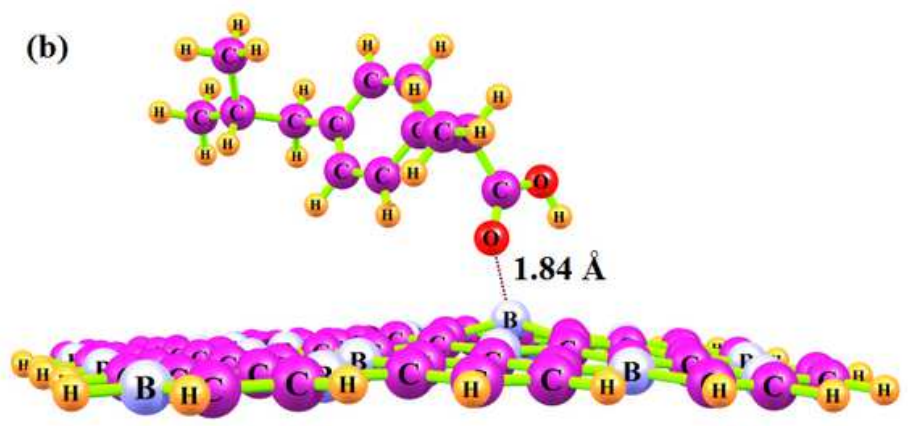

Figure 3

Different optimized configurations (a) I and (b) II of IBP-BC3 complex.

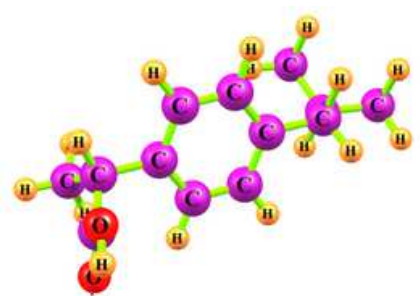

$1.62 \AA$
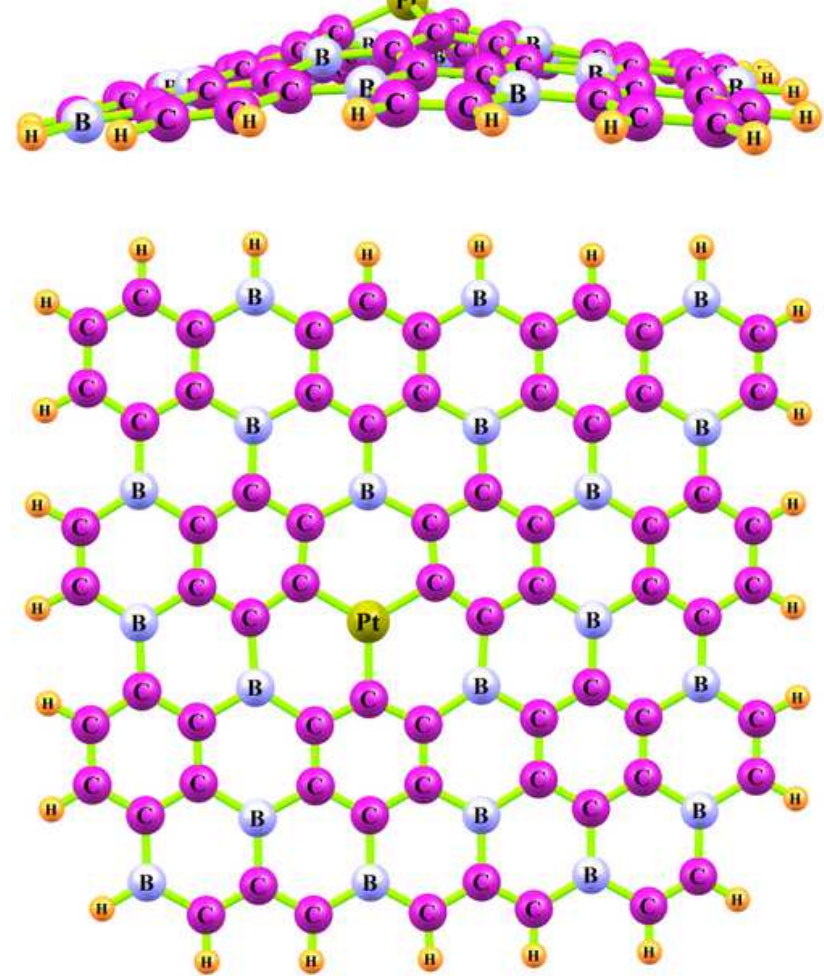

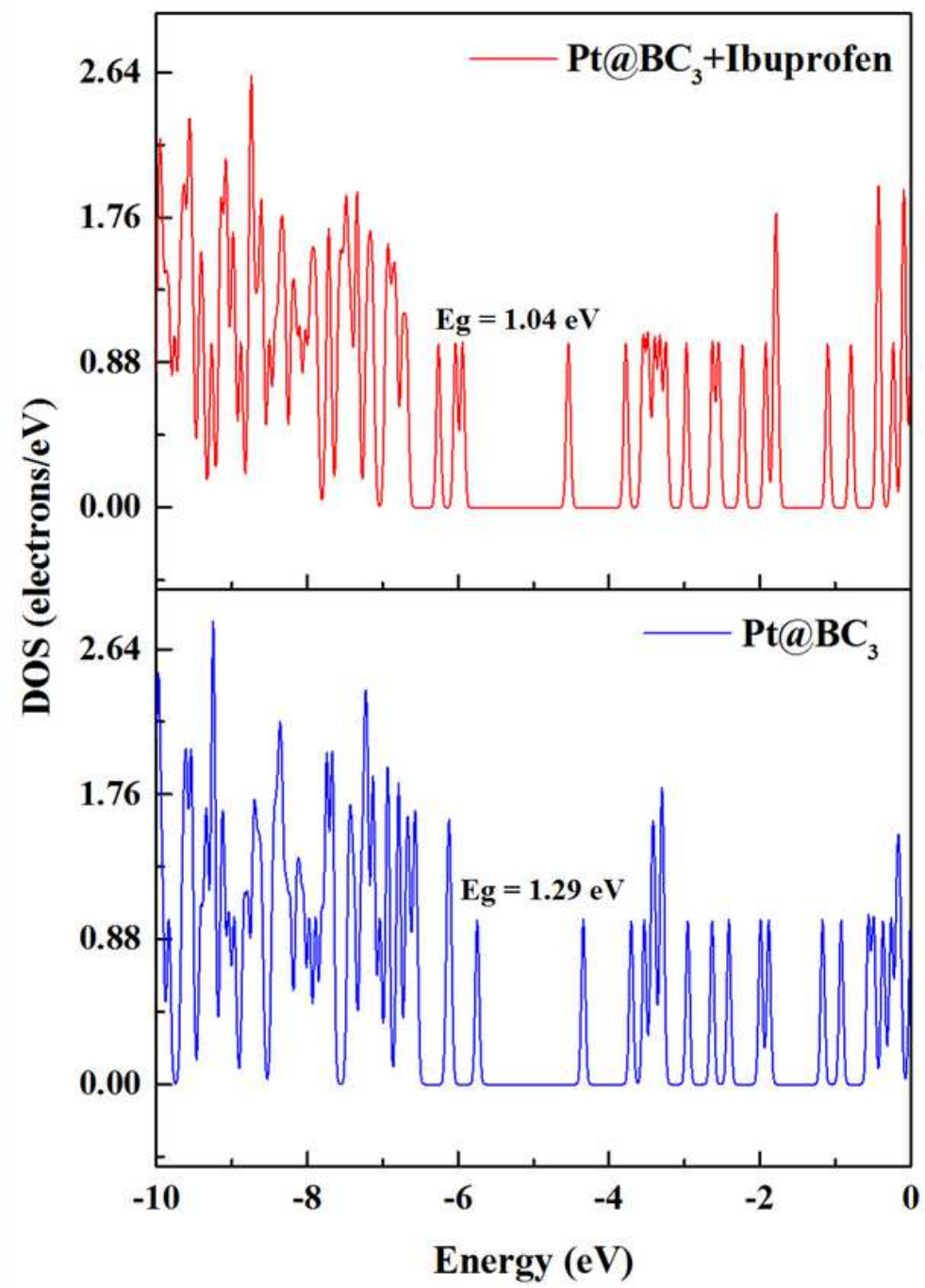

Figure 4 
Optimized structure of (a) Pt@BC3+ IBP, (b) Pt doped BC3 and (c) comparative DOS plots. 